\title{
MINI-OVERVIEW OF VITAMIN K
}

\section{YASSER MOHAMED SHAFIK ${ }^{1}$ AND TOSSON A. MORSY ${ }^{2}$}

Consultant Anesthesia and Pain Management ${ }^{1}$ Military Medical Academy, Cairo, 11291, and Faculty of Medicine ${ }^{2}$, Ain Shams University, Cairo 11566, Egypt ( ${ }^{*}$ Correspondence: yaser0002002@yahoo.com \& morsyegypt2014@gmail.com)

\section{Abstract}

Generally, Vitamins are a number of chemically unrelated families of organic substances that cannot be synthesized by humans but need to be ingested in the diet in small quantities to prevent disorders of metabolism. They are divided into water-soluble and fat-soluble vitamins. Vitamin $\mathrm{K}$ is a group of structurally similar, fat-soluble vitamins found in foods and in dietary supplements. The human body requires vitamin $\mathrm{K}$ for complete synthesis of certain proteins that are needed for blood coagulation or for controlling binding of calcium in bones and other tissues.

Key words: Vitamin K, Medical importance, Safety, Over-dose

\section{Introduction}

Vitamins are a number of chemically unrelated families of organic substances that cannot be synthesized by humans but need to be ingested in the diet in small quantities to prevent disorders of metabolism. They are divided into water-soluble and fat-soluble vitamins (Tab.1). More than 50 years ago, Henrik Dam of Denmark discovered an "anti-hemorrhagic factor" that was capable of reversing dietary-induced bleeding disorders in chicks (Dam, 1935). The name "K" comes from the German/Danish word koagulations vitamin or clotting vitamin (Vermeer and Schurgers, 2000). In 1930, vitamin K was first isolated by Doisy and his colleagues and by Dam from alfalfa sprouts (Dam et al, 1939). When chromatographic techniques were used, the mainstay of vitamin $\mathrm{K}$ isolation was through using chick bioassay (Matschiner and Doisy, 1966).

Sources: Dietary vitamin K1 (phylloquinones) is found in green vegetables like spinach and broccoli. Gut micro-flora synthesizes vitamin $\mathrm{K}_{2}$ (menaquinone), which provides a portion of the dietary requirement of vitamin K (Furie et al, 1999). The various forms of vitamin K2 (MK-4, MK-7, MK-10) are mainly synthesized by bacteria, especially in nutrient products as natto and yogurt (Knapen et al, 2015).

Chemistry: Vitamin $\mathrm{K}$ and its derivatives contain a 2-methyl-1, 4, napthoquinone nucleus with a lipophilic side chain (Fig. 1).

\section{Review, Discussion and Conclusion}

Metabolism: Vitamin K absorption requires intact pancreatic \& biliary function and fat absorptive mechanisms. Dietary vitamin $\mathrm{K}$ is protein-bound liberated by the proteolytic action of pancreatic enzymes in the small intestine. Bile salts then solubilize vitamin $\mathrm{K}$ into micelles for absorption into enterocytes, where it was incorporated into the chylomicrons, thereby facilitating absorption into the intestinal lymphatics and portal circulation for transport to the liver (Shearer, 1995).

Actions: Vitamin $\mathrm{K}$ has a major role in coagulation pathways because it is a cofactor required for the activity of several key proteins containing carboxyglutamic acid residues (Suttie, 2013). In humans, vitamin K functions as a cofactor for the endoplasmic enzyme $\gamma$-glutamylcarboxylase involved in a unique posttranslational carboxylation reaction, in which glutamate residues on various proteins are converted into the $\gamma$ - carboxyglutamate (Gla). This reaction occurs during the last stages of protein synthesis. The resulting Gla residues are characteristic of a limited number of proteins found in liver, bone, and blood vessels (Shearer et al, 2012). The known functional properties of this enzyme include: A carboxylase active site an epoxidase active site A propeptide binding site that allows substrate to attach and shares sequence similarity with propeptide of the carboxy- 
lase substrate (Lin et al, 2002). A propeptide binding site stimulated the carboxylase and epoxidase activity a glutamate binding site (Mutucumarana et al, 2003).

Several other proteins within human body (e.g., osteocalcin) also contain carboxyglutamate residues and depend upon vitamin $\mathrm{K}$ for their activity (Hamidi et al, 2013).

Coagulation pathway: Vitamin $\mathrm{K}$ is essential for the activity of several carboxylase enzymes within the hepatic cells, and therefore is necessary for the activation of coagulation factors VII, IX, X, and prothrombin. These factors contain carboxyglutamic acid, which is carboxylated by gamma-glutamyl carboxylase, an endoplasmic enzyme found in mammalian cells. Vitamin $\mathrm{K}$ is the active coenzyme in this process, providing energy for the reaction through oxidation (Furie and Furie, 1990). After carboxylation, these proteins gain affinity for the negatively charged phospholipids on the surface of platelets and promote coagulation (Davie, 1995).

Antithrombotic effects of proteins $\mathrm{C}$ and $\mathrm{S}$ : Vitamin K-dependent proteins concentrated by the ordinary barium citrate adsorption were first separated into four fractions, fractions $\mathrm{A}, \mathrm{B}, \mathrm{C}$, and $\mathrm{D}$, by DEAE-Sephadex A-50 chromatography. From the pooled fraction A, protein S, factor IX, and prothrombin were purified by column chromatography on Blue-Sepharose CL-6B. Heparin-Sepharose chromatography of the pooled fraction B provided mainly pure factor IX, in addition to the homogeneous prothrombin. A high degree of resolution of protein $\mathrm{C}$ and prothrombin from the pooled fraction $\mathrm{C}$ was obtained with a Blue-Sepharose column. This dye-ligand chromatographic procedure was also very effective for the separation of protein $\mathrm{Z}$ and factor $\mathrm{X}$ contained in pooled fraction $\mathrm{D}$ (Hashimoto, et al, 1985). Protein $\mathrm{C}$, following its activation by thrombin, inactivates factors Va and VIIIa, thus inhibiting excess generation of thrombin (Taylor et al, 1992). Generally Protein C (PC) deficiency is a heritable or acquired risk factor for thrombophilia, with presentations variation from asymptomatic to venous thromboembolism to neonatal purpura fulminans, a lifethreatening disorder. Hereditary PC deficiency is caused by mutation in the PC (PROC) gene located on chromosome $2 q 14.3$. Heterozygous and acquired PC deficiencies are more common than homozygous deficiency (Dinarvand and Moser, 2019). By monitoring the activation of protein $\mathrm{C}$ and the regulation of factor Xa-catalyzed thrombin formation by the activated protein C (APC) on surface of human umbilical vein endothelial cells (HUVEC), functional protein C was synthesized in cultured HUVEC and expressed thereon in the presence of vitamin $\mathrm{K}$ indicating that blood coagulation was regulated by endogenously generated and activated protein $C$, together with or without protein $S$, via inactivation of factor $\mathrm{Va}$ on the surface of endothelial cells (Tanabe et al, 1991).

Mechanism of the coumarin-like family: Coumarin-like anticoagulants that were similar in structure to vitamin K (Fig. 1), interrupt the vitamin $\mathrm{K}$ dependent carboxylation cycle by blocking reduction of the inactive vitamin $\mathrm{K} 2,3$ epoxide to the active form of the vitamin (Clark, 2018). Vitamin K administration is one of the methods used to reverse the effects of coumarin, and timely reversal of excessive anticoagulation is important in preventing bleeding complications. The use of vitamin $\mathrm{K}$ in correcting over-anticoagulation was widely accepted to be superior to discontinuation of therapy but its effectiveness and safety in large scale cohort studies was not been assessed (Denas et $a l$, 2009). Also, low-dose oral vitamin $\mathrm{K}$ did not reduce bleeding in warfarin recipients with international normalized ratio (INRs) of 4.5 to 10.0 and its effects on bleeding events were uncertain (Crowther et al, 2009).

However, since carboxylation of the coagulation factors occurs in the liver, patients with severely impaired liver function do not respond well to vitamin $\mathrm{K}$ supplementation, and the coagulopathy is not as easily reversed. In such cases, fresh frozen plasma and/or coagulant protein concentrates can be used 
to restore coagulant activity (Larson et al, 1981). The liver is an essential player in the pathway of coagulation in both primary and secondary hemostasis. If only von Willebrand factor (VWF) or blood glycoprotein involved in hemostasis was not synthetized by the liver, thus liver failure would be associated with impairment of coagulation. However, the delicate balance between pro and antithrombotic factors synthetised by the liver might be reset to a lower level in patients with chronic liver disease (Lisman et al, 2002). When end stage liver disease occurs, liver transplantation is the only treatment available, which can restore normal hemostasis, and correct genetic clotting defects, such as haemophilia or factor V Leiden mutation. During liver transplantation hemorrhage may result from the pre-existing hypercoagulable state, the collateral circulation caused by portal hypertension and increased fibrinolysis which occurs during this surgery (Senzolo et al, 2006).

Bone formation: Vitamin $\mathrm{K}$ is a cofactor for some proteins involved in bone mineralization, including osteocalcin (bone Gla protein) and matrix Gla protein (Oliveira et al, 2020). A vitamin K2 preparation (menatetrenone) is available in some countries for the treatment of osteoporosis. Generally, bone is a metabolically active tissue that renews itself throughout one's life and Cytokines along with several hormonal, nutritional, and growth factors were involved in tightly regulated bone remodeling (Adams and Pepping, 2005). Thus, prevention and treatment of osteoporosis consists of non-drug and drug or hormonal therapy (Rosen, 2005) Hirota and Hirota (2015) in Japan recommended higher calcium intake than $800 \mathrm{mg} /$ day from dairy and Tofu products, higher intake of vitamin $\mathrm{D}$ than $10 \mu \mathrm{g} / \mathrm{day}$ from fish, and higher intake of vitamin $\mathrm{K}$ from vegetables should be recommended in Japanese postmenopausal osteoporotic patients. Villa et al. (2017) in Brazil mentioned that the osteoporosis was a public health concern associated with an increased risk of bone fractures and vascular calcification. They added that vitamin $\mathrm{K}$ showed unique benefits on these issues, although understudied. The two main vitamin $\mathrm{K}$ forms are phylloquinone (vitamin $\mathrm{K}_{1}$ ) and menaquinone (vitamin $\mathrm{K}_{2}$ ). Caliskan et al. (2017) reported that patients taking warfarin had more bleeding compared to patients taking direct oral anticoagulants after tooth extractions. They added that in patients taking direct oral anticoagulants simple tooth extractions can be safely occurred, without altering the anticaogulant regimen with the use of local hemostatic agents. Multiple dietary components potentially affect osteocyte function and therefore may have a synergistic effect on bone health when combined with a regime of physical activity. Akbari and Rasouli-Ghahroudi (2018) in Tehran reported that vitamin $\mathrm{K}$ exerted its anabolic effect on bone turnover in different ways such as promoting osteoblast differentiation, upregulating transcription of specific genes in osteoblasts, and the activating bone-associated vitamin $\mathrm{K}$ dependent proteins that played critical roles in the extracellular bone matrix mineralization. They added that there was also credible evidence to support the vitamin $\mathrm{k}_{2}$ effects on the differentiation of other mesenchymal stem cells into osteoblast. Ambrożewicz et al. (2019) in the Netherlands in-vitro suggested that proliferation and differentiation of human osteoblasts was strongly influenced by redox balance that altered in the hydroxyapatite-based bio-materials. ROS production and thus induced lipid peroxidation with 4-HNE generation might be important for the redox homeostasis of the growing osteoblasts, whereas vitamins $\mathrm{D}^{3}$ and/or $\mathrm{K}$ prevented oxidative stress of osteoblasts caused by the biomaterials, thereby preventing their adverse effects on proliferation and osteoblasts differentiation. Simes et al. (2019) in Portugal found that vitamin $\mathrm{K}$ is a multifunctional micronutrient implicated in age-related diseases such as cardiovascular diseas es, osteoarthritis and osteoporosis. Although vitamin K-dependent proteins (VKDPs) have a crucial role in the pathogenesis of these 
diseases, novel roles have emerged for vitamin $\mathrm{K}$, independently of its role in VKDPs carboxylation. Vitamin $\mathrm{K}$ act as an anti-inflammatory by suppressing nuclear factor- $\kappa \mathrm{B}$ $(\mathrm{NF}-\mathrm{kB})$ signal transduction and to exert the protective effect against oxidative stress by blocking the gene ration of reactive oxygen species (Fujii et al, 2015). Harshman and Shea (2016) indicated that a high vitamin K status can exert a protective role in inflammatory and mineralization processes associated with the onset and progression of agerelated diseases. They added that vitamin $\mathrm{K}$ involvement as a protective super-micronutrient in aging and 'inflammation' is arising, highlighting its future use in clinical practice. This review summarized current clinical knowledge regarding the vitamin $\mathrm{K}$ in the skeletal and cardiovascular health.

Deficiency: Clinical signs and symptoms of vitamin $\mathrm{K}$ deficiency include easy bruisability, mucosal bleeding, splinter hemorrhpages, melena, hematuria, or any other manifestations of impaired coagulation. Vitamin $\mathrm{K}$ deficiency in an otherwise healthy adult is rare. This is largely due to the wide distribution of phylloquinone in plants, menaquinone production by gut micro-flora, and because vitamin $\mathrm{K}$ is easily recycled within cells (Fig. 2). However, an acquired deficiency may result secondary to drugs such as antibiotics. Patients on total parenteral nutrition and long-term antibiotics are prone to develop vitamin $\mathrm{K}$ deficiency and require supplementation. Beta-lactam antibiotics may be associated with immune-mediated destruction of polymorphonuclear leukocytes, characterized by an abrupt onset of neutropenia with fever, rash, and eosinophilia (Novak et al, 2000). Also, beta-lactam antibiotics may cause immune-mediated hemolytic anemia characterized by a positive non-gamma Coombs' test or subacute extravascular hemolysis with a positive gamma Coombs' test, which generally requires prolonged, highdose therapy and signs of hypersensitivity are usually absent (Tan and File, 1995). Broad spectrum antibiotic therapy suppresses gut flora and contributes to vitamin $\mathrm{K}$ deficiency. Hypoprothrombinemia is a particular problem with antibiotics containing N-methylthiotetrazole side chain, such as cefotetan and cefoperazone may be associated with intolerance to ethanol (Sattler et al, 1986). Prolonged fasting or starvation also decreased the vitamin K levels. Such patients were more sensitive to be treated with coumadinbased anticoagulants (Cushman et al, 2001).

Antibiotics can contribute to vitamin $\mathrm{K}$ deficiency by affecting intestinal bacteria, and also through direct effects on vitamin $\mathrm{K}$ activation in the liver. Most of the ingested vitamin $\mathrm{K}$ is absorbed in the distal small intestine. Many microorganisms colonize the colon and distal ileum; synthesize absorbable vitamin $\mathrm{K}_{2}$. Many broad-spectrum antibiotics diminished this population of bacteria, limiting the menaquinone production (Hooper et al, 1980). The second and third generation antibiotics were associated with hypoprothrombinemia and have a weak coumarin-like effect in patients with low vitamin $\mathrm{K}$ stores and cause vitamin $\mathrm{K}$ deficiency by inhibiting the function of vitamin $\mathrm{K}$ epoxide reductase enzyme in the liver, therefore impairing the recycling of vitamin K (Shearer et al, 1988). Extremely high doses of vitamin E \& A antagonize vitamin K (Light et $a l$, 1944). Hypervitaminosis A appears to reduce absorption of vitamin $\mathrm{K}$, as the parenteral infusion of vitamin A (retinoic acid) did not increase vitamin $\mathrm{K}$ requirement (Smith and Goodman, 1976). Vitamin E in very high doses caused vitamin K deficiency, but did'nt affect absorption (Bettger et al, 1982).

Vitamin $\mathrm{K}$ in surgery: Bariatric surgery proved to be an effective treatment for obesity and obesity-related conditions, as diabetes type 2, hypertension, hyper-lipidemia \& women of childbearing years (Buchwald et $a l, 2004)$. Although the American Society for Metabolic and Bariatric Surgery recommends DCP as a test to determine vitamin K adequacy, none studied pre- or post-RYGB patients with the current available commercially test, which was not FDA approved as 
a vitamin $\mathrm{K}$ biomarker (Bartholomay et al, 2019). Studies identified that vitamin $\mathrm{K}$ inadequacy during pregnancy and in persons seeking bariatric surgery by measuring serum phylloquinone or DCP concent rations, or the combination of both (Ewang-Emukowhate et al, 2015)

Vitamin $\mathrm{K}$ deficient bleeding in the newborn: Vitamin $\mathrm{K}$ deficiency is common in the newborn. This is due to an immature liver, low vitamin $\mathrm{K}$ content of breast milk, a sterile gut, and poor placental transfer of vitamin K (Olson and Vitamin, 2000), as well as infants with intracranial bleeds resulting from vitamin $\mathrm{K}$ inadequacy born to women who have had bariatric surgery (Eerdekens et al, 2010). In infants, plasma concentrations of all vitamin $\mathrm{K}$ dependent factors are about $20 \%$ of adult values. Within a month after birth, the levels rise to within normal limits. Infants without risk for developing vitamin $\mathrm{K}$ deficient bleeding (VKDB), and previously known as newborn hemorrhagic disease were associated with cutaneous, gastrointestinal, and intracranial bleeding in neonates, typically developed within the first week of life (Sankar et al, 2016). The risk of developing VKDB increased with the maternal ingestion of coumarin, certain antibiotics (as cephalosporin), and some anti-convulsants during pregnancy (Motohara et al, 1985). Role of vitamin K prophylaxis in preventing new-born hemorrhagic disease was well known, but with differed opinions on the general and selective prophylaxis i.e. prophylaxis only for the new-born at risk and a marked reduction in hemorrhagic disease incidence of newborn, particularly after the availability of neonatal intensive care unit, which was attributed to effectiveness of vitamin $\mathrm{K}$ prophylaxis and better neonatal care and observation (Bindra, 1986).

Vitamin K and CNS: the role for vitamin $\mathrm{K}$ was demonstrated in target organs, such as the central nervous system (Presse et al, 2009; Ferland, 2012a). At the neuronal level, vitamin $\mathrm{K}$ was involved in the synthesis of sphingolipids-a major constituent of the my- elin sheath and neuronal membranes-and biological activation of vitamin K-dependent proteins (VKDPs) involved in neuronal physiology and survival (Ferland, 2012b). Insufficient levels of vitamin $\mathrm{K}$ may, instead, caused neuropathological dysfunction (Hall et $a l, 1980)$. Besides, there was significant ass ociation between higher serum phylloquinone concentration $\left(\mathrm{K}_{1}\right)$ and better verbal episodic memory performance in older adults (Presse et al, 2013). The use of vitamin K antagonists (VKAs) that depleted its active form was associated with cognitive impairment (Annweiler et al, 2015a) and a lower volume of gray matter in the hippocampus among geriatric patients (Annweiler et al, 2015b). Chouet et al. (2015) found a clinical and statistic significant association between increased dietary phylloquinone intake and better cognition and behavior among geriatric patients. Thus, there was a strong need for novel effective preventive and therapeutic strategies for cognitive decline and dementia. The potential role of vitamin $\mathrm{K}$ in the development of dementia is therefore of substantial interest.

Vitamin $\mathrm{K}$ and cancer patients: Zhang et al. (2001) In vitro reported that cancer cells (HSC-2, HSC-3, HL-60) were more sensitive to combined treatment with vitamin $C$ \& $\mathrm{K} 3$, as compared to normal cells. Vita et al. (2011) reported better cytotoxicity of vitamin C \& K3 on glioma cells than on normal brain cells. Ivanova et al. (2018) suggested that vitamin $\mathrm{C} \& \mathrm{~K}$ can sensitize cancer cells to conventional chemotherapy that allowed achievement of a lower drug effective dose and minimizing the harmful side-effects.

Vitamin $\mathrm{K}$ is known to inhibit the growth of many cancer cell lines including HCC (Nishimaki et al, 1999; Lamson et al, 2003). Nouso et al. (2005) reported that an 85-yearold man suffered from $\mathrm{HCV}$ and diabetes mellitus was diagnosed as having hepatocellular carcinoma (HCC) based on high serum alpha-feto-protein (AFP), AFP-L3, des- $\gamma$-carboxy prothrombin levels and typical enhanced pattern on contrast-enhanced $\mathrm{CT}$, who 
chose to take vitamin $\mathrm{K}$, which was reported to suppress the growth of HCC in-vitro. Three months after starting vitamin $\mathrm{K}$, all three tumor markers were normalized and HCC was markedly regressed without enhancement in early arterial phase on CT. But, they could not conclude that administration of vitamin $\mathrm{K}$ caused the regression in this case, which documented regression of HCC during vitamin $\mathrm{K}$ administration. Venous thromboembolism (VTE) in patients with canc er followed an aggressive course, and often resistant to traditional regimens of pharmacological prophylaxis and treatment. Anticoagulant-related bleeding was also common and complicated VTE treatment as well as the cancer therapy. Consequently, the most effective approach to reducing the burden of VTE and its associated morbidity and mortality is to provide appropriate prophylaxis (Lee, 2007). Dahlberg et al. (2017) found that unclinical vitamin $\mathrm{K}$ deficits referred to carboxylation defects of different types of vitamin K-dependent hepatic and extrahepatic so-called Gla proteins without prolongation of the prothrombin time, due to insufficient supply or malabsorption of vitamin $\mathrm{K}$ as well as drug interactions. Blocking carboxylation of vitamin K-dependent proteins with warfarin anticoagulation- what were the risks/benefits for carcinogenesis? They added that studies on both heparin and low molecular weight heparin blocking of the vitamin K-dependent factors X and II showed tumor suppressive effects. The anti-inflammatory effects of vitamin $\mathrm{K}$ have impacted carcinogenesis, but available little data.

Prophylactic vitamin K1 is given to newborns shortly after birth to prevent vitamin $\mathrm{K}$ deficient bleeding (VKDB), previously referred to as hemorrhagic disease of the newborn. In a systematic review of trials that compared either oral or intramuscular administration of vitamin $\mathrm{K}$ to placebo, vitamin $\mathrm{K} 1$ oxide improved biochemical indices of coagulation status during the first week after birth (Puckett and Offringa, 2000). Vitamin $\mathrm{K} 1$ can be given either orally or intra- muscularly. However, currently used oral regimens are less effective than a single intramuscular dose of vitamin $\mathrm{K}$ in preventing late-onset VKDB (defined as bleeding disorder due to vitamin $\mathrm{K}$ deficiency in infants between two weeks and two months of age (Wariyar et al, 2000).

Toxicity: Vitamin K toxicity is extremely rare. When toxicity does occur, it manifests with signs of jaundice, hyperbilirubinemia, hemolytic anemia, and kernicterus in infants. Vitamin $\mathrm{K}$ toxicity is very rare, and a tolerable upper limit for consumption has not been defined. Menadione, one of the precursors of vitamin $\mathrm{K}$, can cause hemolytic anemia, hyperbilirubinemia, jaundice, and kernicterus in infants. Menadione was used in pre-mature or low-birth-weight newborns and precipitated kernicterus only in high doses, but was not widely available (McLaren, 2000).

Daily requirements value: The primary source of vitamin $\mathrm{K}$ in the diet is from leafy green vegetables (Tab. 2). Intake adequacy concentrations set by the US Institute of Medicine were $90 \& 120 \mu \mathrm{g}$ phylloquinone for women and men, respectively, based on the amount needed for adequate blood clotting and calculated phylloquinone intakes from NHANES III and other US population studies (Trumbo et al, 2001). Generally, dietary requirement, expressed as adequate intake (AI) is 90 micrograms daily in women and 120 micrograms daily in men (Booth, 2012).

Interference with oral anticoagulant therapy: In a study of healthy subjects stably anti-coagulated with acenocoumarol, use of food supplements provided with up to $100 \mathrm{mi}$ cro-grams/day of vitamin K1 did not significantly interfere with treatment (Schurgers et al, 2004). The threshold dose of vitamin $\mathrm{K} 1$ causing a statistically significant lowering of INR in these subjects was $150 \mathrm{mg} /$ day, an amount easily exceeded following the ingestion of one-half cup of kale (Tab. 3).

Treatment of coagulopathy: To depend upon the cause of deficiency, vitamin $\mathrm{K}$ can be administered in doses of 1 to $25 \mathrm{mg}$ via oral, intramuscular, subcutaneous, or intravenous 
routes. When vitamin K deficiency occurs in patients who received coumarin-like anticoagulants, doses of vitamin $\mathrm{K}$ should be minimized in order to prevent refractoriness to more anticoagulation. Hanslik and Prinseau (2004) in France reported that the anti-coagulation with antivitamin $\mathrm{K}$ (AVK) proved very effective for primary and secondary prevention of thromboembolic events. However, questions persist about the risks and management of over-anticoagulation. For reversal of excessive anticoagulation by warfarin, AVK withdrawal, oral or parenteral vitamin $\mathrm{K}$ administration, prothrombin complex or fresh frozen plasma may be used, depending on the excess of anticoagulation, the existence and site of active bleeding, patient characteristics and the indication for AVK. In over-anticoagulated patients, vitamin $\mathrm{K}$ aimed at rapid lowering of the international normalized ratio (INR) into a safe range to reduce the risk of major bleeding and therefore improving patient outcome without exposing the patient to the risk of thrombo-embolism due to overcorrection, resistance to AVK, or an allergic reaction to medication. Ansell et al. (2008) in USA recommended that the initiation of the oral anticoagulation therapy, with doses between $5 \mathrm{mg}$ and $10 \mathrm{mg}$ for the first 1 or 2 days for most individuals, with subsequent dosing based on the international normalized ratio (INR) response (Grade 1B); they suggested against pharmacogenetic-based dosing until randomized data indicated that it was beneficial (Grade 2C); and in elderly and other patient subgroups who are debilitated or malnourished, recommended a starting dose of $<$ or 5mg (Grade 1C). They also gave several specific recommendations for the management of patients with nontherapeutic INRs, with INRs above the therapeutic range, and with bleeding whether the INR was therapeutic or elevated. For the use of vitamin K to reverse a mildly elevated INR, oral rather than subcutaneous administration was recommended (Grade 1A). For patients with life-threatening bleeding or intracranial he- morrhage, and recommended the use of prothrombin complex concentrates or recombinant factor VIIa to immediately reverse the INR (Grade 1C). For patients with a lupus inhibitor, a therapeutic target INR of 2.5 (2.0 to 3.0) was recommended (Grade 1A).

Vitamin $\mathrm{K}$ and food bacteria: Many bacteria, as Escherichia coli found in the large intestine, can synthesize vitamin $\mathrm{K}_{2}$ (menaquinone-7 or MK-7, up to MK-11), but not $\mathrm{K}_{1}$ (phylloquinone). In these bacteria, menaquinone transfers two electrons between two different small molecules, during oxygen-independent metabolic energy production processes (anaerobic respiration (Bentley and Meganathan, 1982). A small molecule with an excess of electrons (or an electron donor) as lactate, formate, or NADH, with the help of an enzyme, passes two electrons to menaquinone. The menaquinone, with the help of another enzyme, then transfers these two electrons to a suitable oxidant, such as fumarate or nitrate (or an electron acceptor), added 2 electrons to fumarate or nitrate converted molecule to succinate or nitrite \& water respectively (Haddock and Jones, 1977).

LeBlanc et al. (2013) in Argentina found that food-related lactic acid bacteria (LAB) as well as human gut commensals such as Bifidobacterium can de novo synthesize and supply vitamins. This was important since humans lack the biosynthetic capacity for most vitamins and these must thus be provided exogenously.

Laboratory evaluation of vitamin $\mathrm{K}$ : There was no consensus as to a best method for assessing vitamin $\mathrm{K}$ status (Shea and Booth, 2016). The undercarboxylated prothrombin (DCP) and undercarboxylated osteocalcin (uc-OC) proved to be sensitive measures of vitamin $\mathrm{K}$ status. Both plasma phyllo-qui none and uc-OC were affected by recent dietary vitamin $\mathrm{K}$ intake as a higher uc-OC was associated with a lower vitamin $\mathrm{K}$ intake and low serum phylloquinone, and low serum phylloquinone also reflected low tissue reserves (Hayes et al, 2016). However, uc-OC proved to be the first indicator of vitamin $\mathrm{K}$ 
inadequacy and the last to respond to supplementation (Krzyzanowska et al, 2015). Perhaps the body preferentially uses vitamin $\mathrm{K}$ for blood clotting and, if stores were adequate for that purpose, the remaining supply was used to support other functions. Because the ASMBS lists osteoporosis as a symptom requiring investigation of vitamin $\mathrm{K}$ concentration, measurement of uc-OC might be an option because $\gamma$-carboxylation of osteocalcin is necessary for osteoblast function in bone matrix metabolism (Akbari and Rasouli-Ghahroudi, 2018). This provided insight into osteopenia and osteoporosis reported in persons after bariatric surgery (Scibora et al, 2012).

Nevertheless, vitamin K status can be determined indirectly by measuring vitamin $\mathrm{K}$ dependent factors (i.e., prothrombin, factors VII, IX, X, or protein C). In patients who are vitamin $\mathrm{K}$ deficient, levels of these factors often are less than $50 \%$ of normal (Kapadia and Bona, 2008). Measurement of desgamma-carboxyprothrombin (DCP) in plasma was another more sensitive way of determining vitamin $\mathrm{K}$ deficiency. In normal subjects, DCP is zero; it is elevated in vitamin $\mathrm{K}$ deficiency from whatever cause and/or liver disease (Blanchard et al, 1983)

Prevention of vitamin $\mathrm{K}$ deficient bleeding in newborns: There is general consensus that all babies should receive vitamin K. Standard treatment is with vitamin $\mathrm{K} 1(0.5$ to $1 \mathrm{mg}$ IM) administered at birth. For healthy, exclusively breastfed, term infants, an alternative strategy may be oral vitamin K1 (2mg PO with the first feed and at one, four, and eight weeks of age). However, oral supplements may be less effective in preventing late-onset vitamin $\mathrm{K}$ deficient bleeding in infants, and no approved oral preparation is available in the United States. (A newborn should have a thorough evaluation performed within 24 hours of birth to identify any abnormality that would alter the normal newborn course or identify a medical condition that should be addressed as e.g., anomalies, birth injuries, jaundice, or cardiopul- monary disorders as well as the maternal, family, and prenatal history and a complete examination (Lissauer, 2006) Neonatal hemodynamic assessment was rather complex and encompassed more than solely monitoring HR, blood pressure, and other inaccurate clinical pictures (de Boode et al, 2018).

The Adequate Intake for vitamin $\mathrm{K}$, as defined by the Food and Nutrition Board is not increased for lactating mothers. However, one study suggests that exclusively breastfed infants often have low plasma vitamin $\mathrm{K}$ concentrations, and that this can be prevented by supplementation of the mothers' diet with $5 \mathrm{mg}$ of vitamin $\mathrm{K}_{1}$ (phylloquinone) throughout the first 12 weeks of life (Greer, 2001).

However, none evaluated whether maternal supplementation with vitamin $\mathrm{K}$ has any clinically important benefits. But, the multiple-micronutrient (MMN) deficiencies often coexist among reproductive age women in low- to middle-income countries. They were exacerbated in pregnancy due to the increased demands, leading to potentially adverse effects on the mother and developing fetus. Though supplementation with MMNs was recommended earlier because of impact on pregnancy evidence outcomes, a consensus was yet to be reached as to replace iron and folic acid supplementation with MMNs (Haider and Bhutta, 2017).

\section{Conclusion}

Vitamin $\mathrm{K}$ is a multifunctional micronutrient implicated in age-related diseases such as cardiovascular diseases, osteoarthritis and osteoporosis. It is essential for the synthesis of coagulation proteins. It is a co-factor for vitamin $\mathrm{K}$ dependent carboxylation, which includes various enzymes. Vitamin $\mathrm{K}$ has a plethora of potential implications, including prevention and treatment of arterial calcifications, coronary heart disease and cancer, improvements in bone strength and reduced risks of fractures as well as improvements in insulin sensitivity. Available clinical evidences indicate that a high vitamin $\mathrm{K}$ status can exert a protective role in the inflammat- 
ory and mineralization processes associated with the onset and progression of age-related diseases.

Signs and symptoms include: bruising, petechiae, hematomas, oozing of blood at surgical or puncture sites, stomach pains; risk of massive uncontrolled bleeding; cartilage calcification; and severe malformation of developing bone or deposition of insoluble calcium salts in the walls of arteries. In infants, some birth defects such as underdeveloped face, nose, bones, and fingers.

\section{References}

Adams, J, Pepping, J, 2005: Vitamin K in the treatment and prevention of osteoporosis and arterial calcification. Am. J. Hlth. Syst. Pharm. 62, 15:1574-81.

Akbari, S, Rasouli-Ghahroudi, A, 2018: Vitamin $\mathrm{K}$ and bone metabolism: a review of the latest evidence in preclinical studies. Bio-Med. Res. Int. 4629383:8.10.1155/4629383.

Akbari' S, Rasouli-Ghahroudi, AA, 2018: Vitamin $\mathrm{K}$ and bone metabolism: A review of the la-test evidence in preclinical studies. Biomed. Res. Int. Jun 27; 2018:4629383. Doi: 10.1155/ 2018/4629383

Annweiler, C, Denis, S, Duval, G, Ferland, G, Bartha, R, et al, 2015a: Use of vitamin $\mathrm{K}$ antagonists and brain volumetry in seniors: Preliminary results from the GAIT study. J. Gerontol. A Biol. Sci. Med. Sci. 63, 10:2199-202

Annweiler, C, Ferland, G, Barberger-Gateau, P, Brangier, A, Rolland, Y, et al, 2015b: Vitamin $\mathrm{K}$ antagonists and cognitive impairment: Results from a cross-sectional pilot study among geriatric patients. J. Gerontol. A Biol. Sci. Med. Sci. 70:97-101.

Ansell, J, Hirsh, J, Hylek, E, et al, 2008: Pharmacology and management of the vitamin $\mathrm{K}$ antagonists: American College of Chest Physicians Evidence-Based Clinical Practice Guidelines ( $8^{\text {th }}$ Edition). Chest 133, 6:S160-98

Bartholomay, LM, Berlin, K, McInerney, M, Garcia, L, 2019: Vitamin K status in women of childbearing years before or after bariatric surgery. Curr. Dev. Nutr. 3, 7:nzz056. doi: 10.1093/ cdn/nzz056

Bentley, R, Meganathan, R, 1982: Biosynthesis of vitamin $\mathrm{K}$ (menaquinone) in bacteria. Microbiol. Rev. 46, 3:241-80.
Bettger, WJ, Jones, JP, Olson, RE, 1982: Effect of alpha-tocopherol and alpha-tocopherolquinone on vitamin K-dependent carboxylation in the rat. Fed. Proc. 41:344-7.

Bindra, AP, 1986: Role of vitamin K prophylaxis in newborn. Padiatr. Padol. 21, 2:111-7.

Blanchard, RA, Furie, BC, Kruger, SF, et al, 1983: Immunoassays of human prothrombin species which correlate with functional coagulant activities. J. Lab. Clin. Med. 101:242-6.

Booth, SL, 2012: Vitamin K: Food composition and dietary intakes. Food Nutr. Res.56. Doi: 10.

13402/fnr.v56i0.5505

Buchwald, H, Avidor, Y, Braunwald, E, Jensen, M, Pories, W, et al, 2004: Bariatric surgery: A systematic review \& meta-analysis. JAMA 292:1724-37

Caliskan, M, Tükel, HC, Benlidayi, E, Deniz, A, 2017: Is it necessary to alter anticoagulation therapy for tooth extraction in patients taking direct oral anticoagulants? Med. Oral Patol. Oral Cir. Bucal. 22, 6:e767-73.

Chouet, J, Ferland, G, Féart, C, Rolland, Y, Presse, N, et al, 2015: Dietary vitamin K intake is associated with cognition and behavior among geriatric patients: The CLIP study. Nutrients 7, 8: 6739-50.

Clark, DB, 2018: Factor IX complex concentrates. In: Hematology Preparation of PlasmaDerived and Recombinant Human Plasma Proteins ( $7^{\text {th }}$ Edition),

Crowther, MA, Ageno, W, Garcia, D, Wang, L, Witt, DM, et al, 2009: Oral vitamin K versus placebo to correct excessive anticoagulation in patients receiving warfarin: A randomized trial. Ann. Intern. Med. 150, 5:293-300.

Cushman, M, Booth, SL, Possidente, CJ, et al, 2001: The association of vitamin $\mathrm{K}$ status with warfarin sensitivity at the onset of treatment. $\mathrm{Br}$. J. Haematol. 112:572-8.

Dahlberg, S, Ede, J, Schött , U, 2017: Vitamin $\mathrm{K}$ and cancer. Scand. J. Clin. Lab. Invest. 77, 8: 555-67.

Dam, H, 1935: The antihemorrhagic vitamin of the chick: Occurrence and chemical nature. Nature 135:652-60.

Dam, H, Geiger, A, Glavind, J, et al, 1939: Olierung des Vitamins $\mathrm{K}$ in hochgereinigter form. Helv. Chim. Acta 22:310-6.

Davie, EW, 1995: Biochemical and molecular aspects of the coagulation cascade. Thromb. Haemost. 74:1-8. 
de Boode, WP, van der Lee, R, Eriksen, B H, Nestaas, E, Dempsey, E, et al, 2018: The role of neonatologist performed echocardiography in the assessment and management of neonatal shock. Pediatr. Res. 84, 1:S57-67.

Denas, G, Marzot, F, Offelli, P, Stendardo, A, Cucchini, U, et al, 2009: Effectiveness and safety of a management protocol to correct over-anticoagulation with oral vitamin $\mathrm{K}$ : A retrospective study of 1,043 cases. J. Thromb. Thrombolysis $27,3: 340-7$

Dinarvand, P, Moser, KA, 2019: Protein C deficiency. Arch. Pathol. Lab. Med. 143, 10:12815.

Eerdekens, A, Debeer, A, van Hoey, G, DeBorger, C, Sachar, V, et al, 2010: Maternal bariatric surgery: Adverse outcomes in neonates. Eur. J. Pediatr 169:191-6.

Ewang-Emukowhate, M, Harrington, D, Bot ha, A, McGowan, B, Wierzbicki, 2015: A vitamin $\mathrm{K}$ and other markers of micronutrient status in morbidly obese patients before bariatric surgery. Int. J. Clin. Pract. 69:638-42.

Ferland, G, 2012: Vitamin $\mathrm{K}$ and the nervous system: An overview of its actions. Adv. Nutr. 3:204-12.

Ferland, G, 2012: Vitamin K, an emerging nutrient in brain function. Biofactors 38:151-7.

Fujii, S, Shimizu, A, Takeda, N, Oguchi, K, Katsurai, T, et al, 2015: Systematic synthesis and anti-inflammatory activity of $\omega$-carboxylated menaquinone derivatives: Investigations on identified and putative vitamin $\mathrm{K}_{2}$ metabolites. Bioorg. Med. Chem. 23:2344-52.

Furie, B, Bouchard, B, Furie, BC, 1999: Vitamin K-dependent biosynthesis of gamma-carboxy-glutamic acid. Blood 93:1798-9.

Furie, B, Furie, BC, 1990: Molecular basis of vitamin K-dependent gamma-carboxylation. Blood 75:1753-9.

Greer, FR, 2001: Are breast-fed infants vitamin K deficient? Adv. Exp. Med. Biol. 501:391-5.

Haddock, BA, Jones, CW, 1977: Bacterial respiration. Bacteriol. Rev. 41, 1:47-99.

Haider, BA, Bhutta, ZA, 2017: Multiple-micronutrient supplementation for women during pregnancy. Cochrane Database Syst. Rev. 4, 4C D004905. doi: 10.1002/14651858.CD004905

Hall, JG, Pauli, RM, Wilson KM, 1980: Maternal and fetal sequelae of anticoagulation during pregnancy. Am. J. Med. 68:122-40.

Hamidi, MS, Gajic-Veljanoski, O, Cheung,
AM, 2013: Vitamin $\mathrm{K}$ and bone health J. Clin. Densitom. 4:409-13.

Hanslik, T, Prinseau, J, 2004: The use of vitamin $\mathrm{K}$ in patients on anticoagulant therapy: A practical guide. Am. J. Cardiovasc. Drugs 4, 1: 43-55

Harshman, SG, Shea, MK, 2016: The role of vitamin $\mathrm{K}$ in chronic aging diseases: Inflammation, cardiovascular disease, and osteoarthritis. Curr. Nutr. Rep. 5, 2:90-8.

Hashimoto, N, Morita, T, Iwanaga, S, 1985: A method for systematic purification from bovine plasma of six vitamin K-dependent coagulation factors: Prothrombin, factor X, factor IX, protein S, protein C, and protein Z. J. Biochem. 97, 5: 1347-55.

Hayes, A, Hennessy, A, Walton, J, McNulty, B, Lucey, A, et al, 2016: Phylloquinone intakes and food sources and vitamin $\mathrm{K}$ status in a nationally representative sample of Irish adults. J. Nutr. 146:2274-80.

Hirota, T, Hirota, K, 2015: Bone and nutrition: Nutritional osteoporosis management. Clin. Calcium 25, 7:1049-55.

Hooper, CA, Haney, BB, Stone, HH, 1980: Gastrointestinal bleeding due to vitamin K deficiency in patients on parenteral cefamandole. Lancet 1:39-41.

Ivanova, D, Zhelev, Z, Getsov, P, Nikolova, B, Aoki, I, et al, 2018: Vitamin K: Redox-modulation, prevention of mitochondrial dysfunction and anticancer effect. Redox Biol. 16: 352-8.

Kapadia, P, Bona, R, 2008: Acquired deficiency of vitamin K-dependent clotting factor due to brodifacoum ingestion. Conn. Med. 72, 4:207-9.

Knapen, MH, Braam, LA, Teunissen, KJ, Zwijsen, RM, et al, 2015: Yogurt drink fortified with menaquinone-7 improves vitamin $\mathrm{K}$ status in a healthy population. J. Nutr. Sci. 4:e35.

Krzyzanowska, P, Pogorzelski, A, Skorupa, W, Moczko, J, Grebowiec, P, et al, 2015: Exogenous and endogenous determinants of vitamin K status in cystic fibrosis. Sci. Rep. 5:12000-8.

Lamson, DW, Plaza, SM, 2003: The anticancer effects of vitamin K. Altern. Med. Rev. 8:30318.

Larson, AE, Friedman, PA, Suttie, JW, 1981: Vitamin K-dependent carboxylase: Stoichiometry of carboxylation and vitamin K 2, 3-epoxide formation. J. Biol. Chem. 256:11032-6.

LeBlanc, JG, Milani, C, de Giori, GS, Sesma, F, van Sinderen, D, et al, 2013: Bacteria as 
vitamin suppliers to their host: A gut microbiota perspective. Curr. Opin. Biotechnol. 24, 2:160-8. Lee, AYY, 2007: Prevention of deep vein thrombosis in cancer patients. Semin. Thromb. Hemost. 33, 7:699-706.

Light, RF, Alscher, RP, Frey, CN, 1944: Vitamin A toxicity and hypoprothrombinemia. Science 100:225-9.

Lin, PJ, Jin, DY, Tie, JK, et al, 2002: The putative vitamin K-dependent gamma-glutamyl carboxylase internal propeptide appears to be the propeptide binding site. J. Biol. Chem. 277: 28584.

Lisman, T, Leebeek, FW, de Groot, PG, 2002: Haemostatic abnormalities in patients with liver disease. J. Hepatol. 37:280-7.

Lissauer, T, 2006: Physical examination of the newborn. In: Neonatal-Perinatal Medicine: Diseases of the Fetus and Infant, $8^{\text {th }}$ ed, Fanaroff, AA, Martin, RJ, Walsh, MC, (Eds.), Mosby, St Louis.

Matschiner, JT, Doisy, EA, Jr, 1966: Bioassay of Vitamin K in chicks. J. Nutr. 90, 1:97-100.

McLaren, D, 2000: Clinical manifestations of human vitamin and mineral disorders. In: Modern Nutrition in Health and Disease, Shils, M, Olson, J, Shike, M, et al, (Eds.), Lippincott, Philadelphia.

Motohara, K, Endo, F, Matsuda, I, 1985: Effect of vitamin $\mathrm{K}$ administration on acarboxy prothrombin (PIVKA-II) levels in newborns. Lancet $2: 242-5$

Mutucumarana, VP, Acher, F, Straight, D, et al, 2003: A conserved region of human vitamin K-dependent carboxylase between residues 393 and 404 is important for its interaction with the glutamate substrate. J. Biol. Chem. 278:46488.

Nishimaki, J, Miyazawa, K, Yaguchi, M, Katagiri, T, Kawanishi, Y, et al, 1999: Vitamin K2 induces apoptosis of a novel cell line established from a patient with myelodysplastic syndrome in blastic transformation. Leukemia 13:

1399-140.

Nouso, K, Uematsu, S, Shiraga, K, Okamoto, R, Harada, R, et al, 2005: Regression of hepatocellular carcinoma during vitamin $\mathrm{K}$ administion. World J. Gastroenterol. 11, 42:6722-4.

Novak, R, Charpentier, E, Braun, JS, Tuomanen, E, 2000: Signal transduction by a death signal peptide: uncovering the mechanism of bacterial killing by penicillin. Mol. Cell 5:49-52.

Oliveira, RB, Stinghen, AEM, Ziad A Massy, ZA, 2020: Vitamin $K$ role in mineral and bone disorder of chronic kidney disease. Clin. Chim. Act 502:66-72.

Olson, R. Vitamin K, 2000: In: Modern Nutrition in Health and Disease, Shils, M, Olson, J, Shike, M, et al, (Eds.) Lippincott, Philadelphia.

Presse, N, Belleville, S, Gaudreau, P, Greenwood, CE, Kergoat, MJ, et al, 2013: Vitamin $\mathrm{K}$ status and cognitive function in healthy older adults. Neurobiol. Aging 34:2777-83.

Presse, N, Shatenstein, B, Kergoat, MJ, Ferland, G, 2009: Validation of a semi-quantitative food frequency questionnaire measuring dietary vitamin K intake in elderly people. J. Am. Diet. Assoc. 109:1251-5.

Puckett, R, Offringa, M, 2000: Prophylactic vitamin $\mathrm{K}$ for vitamin $\mathrm{K}$ deficiency bleeding in neonates. Cochr. Database Syst. Rev. CD 002776.

Rosen, CJ, 2005: Clinical practice: Postmenopausal osteoporosis. N. Engl. J. Med. 353:59-61

Sankar, MJ, Chandrasekaran, A, Kumar, P, Thukral, A, Agarwal, R, et al, 2016: Vitamin $\mathrm{K}$ prophylaxis for prevention of vitamin $\mathrm{K}$ deficiency bleeding: a systematic review. J. Perinatol. 36, 1:S29-35.

Sattler, FR, Weitekamp, MR, Ballard, JO, 1986: Potential for bleeding with the new betalactam antibiotics. Ann. Intern. Med.105:924-8. Schurgers, LJ, Shearer, MJ, Hamulyak, K, et al, 2004: Effect of vitamin $K$ intake on the stability of oral anticoagulant treatment: Dose-response relationships in healthy subjects. Blood 104:2682-6.

Scibora, L, Ikramuddin, S, Buchwald, H, Petit, M, 2012: Examining the link between bariatric surgery, bone loss, and osteoporosis: a review of bone density studies. Obes. Surg. 22: 654-67.

Senzolo, M, Burra, P, Cholongitas, E, Burroughs, AK, 2006: New insights into the coagulopath of the liver disease and liver transplantation. World J. Gastroenterol. 12, 48:7725-36.

Shea, M, Booth, S, 2016: Concepts and controversies in evaluating vitamin $\mathrm{K}$ status in population-based studies. Nutrients 8:25-8.

Shearer, MJ, 1995: Vitamin K. Lancet 345: 229-31.

Shearer, MJ, Bechtold, H, Andrassy, K, et al, 1988: Mechanism of cephalosporin-induced hypoprothrombinemia: relation to cephalosporin side chain, vitamin $\mathrm{K}$ metabolism, and vitamin $\mathrm{K}$ status. J. Clin. Pharmacol. 28:88-92.

Shearer, MJ, Fu, X, Booth, SL, 2012: Vitamin $\mathrm{K}$ nutrition, metabolism, and requirements: Cur- 
rent concepts and future research. Adv. Nutr. 3, 2:182-95.

Simes, DC, Viegas, CSB, Araújo, N, Marreiros, C, 2019: Vitamin $\mathrm{K}$ as a powerful microntrient in aging and age-related diseases: Pros and cons from clinical studies. Int. J. Mol. Sci. 20, 17:4150.

Smith, FR, Goodman, DS, 1976: Vitamin A transport in human vitamin A toxicity. N. Engl. J.

Med. 294:805-11.

Suttie, J, 2013: Vitamin K: Biochemistry, Metabolism, and Nutritional Aspects ( ${ }^{\text {nd }}$ Edition), Encyclopedia of Biological Chemistry

Tan, JS, File, TM, Jr, 1995: Antipseudomonal penicillins. Med. Clin. North Am. 79:679-82.

Tanabe, S, Sugo, T, Matsuda, M, 1991: Synthesis of protein $\mathrm{C}$ in human umbilical vein endothelial cells. J. Biochem. 109, 6:924-8.

Taylor, FB, Jr, Hoogendoorn, H, Chang, AC, Peer, G, Nesheim, ME, et al, 1992: Anticoagulant and fibrinolytic activities are promoted, not retarded, in vivo after thrombin generation in the presence of a monoclonal antibody that inhibits activation of protein C. Blood. 79, 7:1720-8.

Vita, MF, Nagachar, N, Avramidis, D, Delwar, ZM, Cruz, MH, et al, 2011: Painkiller effect of prolonged exposure to menadione on glio- ma cells: potentiation by vitamin C. Investig. New Drugs 29:1314-20.

Trumbo, P, Yates, AA, Schlicker, S, Poos, M, 2001: Dietary reference intakes: vitamin A, vitamin $\mathrm{K}$, arsenic, boron, chromium, copper, iod ine, iron, manganese, molybdenum, nickel, silicon, vanadium, and zinc. J. Am. Diet. Assoc. 101, 3:294-301

Vermeer, C, Schurgers, LJ, 2000: A comprehensive review of vitamin $\mathrm{K}$ and vitamin $\mathrm{K}$ antagonists. Hematol. Oncol. Clin. North Am. 14: 339-44.

Villa, JKD, Diaz, MAN, Pizziolo, VR, Martino, HSD, 2017: Effect of vitamin $\mathrm{K}$ in bone metabolism and vascular calcification: A review of mechanisms of action and evidences. Crit. Rev. Food Sci. Nutr. 57, 18:3959-70.

Wariyar, U, Hilton, S, Pagan, J, et al, 2000: Six years' experience of prophylactic oral vitamin K. Arch. Dis. Child Fetal Neonat. 82:F64-9.

Willems, HME, van den Heuvel, EGH, Schoemaker, RJ, Nulend, JK, Bakker, AD, 2017: Diet and Exercise: a Match Made in Bone. Curr. Osteoporos. Rep. 15, 6:555-63.

Zhang, W, Negoro, T, Satoh, K, Jiang, Y, Hashimoto, K, et al, 2001: Synergistic cytotoxic action of vitamin $\mathrm{C}$ and vitamin K3. Anticancer Res. 21:3439-44

Table 1: Function of Vitamin K

\begin{tabular}{|l|l|l|}
\hline \multicolumn{1}{|c|}{ Vitamin K } & \multicolumn{1}{c|}{ Function } & Deficiency syndrome \\
\hline Phylloquinone & Clotting factors, bone proteins & Hemorrhagic diseases \\
\hline Menaquinone & Biological roles in humans and animals & \\
\hline Menadione & Anti-Helobacter pylori and anti-inflammatory & \\
\hline
\end{tabular}

Table 2: Dietary reference intakes for fat-soluble vitamin $\mathrm{K}^{*}$

\begin{tabular}{|c|c|c|c|}
\hline Nutrient & Age group & RDA/AI UL & Adverse effects of excess \\
\hline Vitamin K & Micrograms daily & Micrograms daily & \\
\hline Infants & $0-6$ months 2 & $\mathrm{ND}$ & \multirow{10}{*}{$\begin{array}{l}\text { No adverse effects associ- } \\
\text { ated with vitamin K con- } \\
\text { sumption from food or sup- } \\
\text { plements have been report- } \\
\text { ed, however data are limited. }\end{array}$} \\
\hline & $7-12$ months 2.5 & ND & \\
\hline Children & 1 to 3 years 30 & ND & \\
\hline & 4 to 8 years 55 & ND & \\
\hline Adult males & 9 to 13 years 60 & ND & \\
\hline & 14 to 18 years 75 & ND & \\
\hline & $>19$ years 120 & $\mathrm{ND}$ & \\
\hline Adult females (also pregnancy \& lactation) & 9 to 13 years 60 & $\mathrm{ND}$ & \\
\hline & 14 to 18 years 75 & ND & \\
\hline & $>19$ years 90 & ND & \\
\hline
\end{tabular}

*other names of Vitamin K: Anti-Hemorrhagic Factor, Menadiol, Menadione (Vitamin K-3), Menaquinone (Vitamin K-2), Methyl-Phytyl Naphthaaquinone, Phylloquinone (Vitamin K-1), Phytonadione 
Table 2: Foods with moderate to high levels of vitamin $\mathrm{K}$

\begin{tabular}{|c|c|c|}
\hline Food name & Serving size & Vitamin K (micrograms) \\
\hline \multicolumn{3}{|l|}{ 1- High level vitamin $\mathrm{K}$} \\
\hline Kale, frozen (cooked or boiled, drained) & $1 / 2$ cup & 570 \\
\hline Kale, fresh, (cooked or boiled, drained) & $1 / 2$ cup & 530 \\
\hline Spinach, frozen (cooked or boiled, drained) & $1 / 2$ cup & 514 \\
\hline Spinach, raw & 1 cup & 150 \\
\hline Collard greens, frozen (cooked, drained) & $1 / 2$ cup & 530 \\
\hline Turnip greens, frozen (cooked, drained) & $1 / 2$ cup & 425 \\
\hline Brussels sprouts, frozen (cooked, drained) & $1 / 2$ cup & 110 \\
\hline \multicolumn{3}{|l|}{ 2- Moderate level vitamin $\mathrm{K}$ foods } \\
\hline Asparagus, frozen (cooked, drained) & $1 / 2$ cup or 4 spears & 72 or 48 \\
\hline Broccoli, frozen (cooked, drained) & 4 spears 30 & 30 \\
\hline Broccoli, fresh (cooked, drained) & $1 / 2$ cup 60 & 60 \\
\hline Broccoli, raw & 1 spear 52 & 52 \\
\hline lettuce butter-head (Boston and Bibb lettuces) & $1 / 2 \operatorname{cup} 40$ & 40 \\
\hline Lettuce (iceberg, crisp-head) & $1 / 2$ head 80 & 80 \\
\hline Lettuce (romaine, cos) & $1 / 2$ head 65 & 65 \\
\hline Lettuce (green leaf) & 1 cup 57 & 57 \\
\hline Okra, fresh (cooked, drained) & 1 cup 97 & 97 \\
\hline Okra, frozen (cooked, drained) & $1 / 2$ cup 32 & 32 \\
\hline Cabbage (cooked, drained) & $1 / 2$ cup 44 & 44 \\
\hline Cabbage, raw & $1 / 2 \operatorname{cup} 73$ & 73 \\
\hline Cabbage, savoy (raw) & $1 / 2 \operatorname{cup} 21$ & 21 \\
\hline Cabbage, Chinese (cooked, drained) & $1 / 2 \operatorname{cup} 24$ & 24 \\
\hline Coleslaw (fast food-type) & $1 / 2 \operatorname{cup} 28$ & 28 \\
\hline Sauerkraut, canned & $3 / 4 \operatorname{cup} 56$ & 56 \\
\hline Peas, frozen, with pod (cooked, drained) & $1 / 2$ cup 41 & 41 \\
\hline Peas, fresh, with pod (cooked, drained) & $1 / 2$ cup & 24 \\
\hline Peas, green, frozen (cooked, drained) 1 & $1 / 2$ cup & 20 \\
\hline Celery, raw & $1 / 2$ cup & 18 \\
\hline Beans, green or yellow, fresh (cooked, drained) & $1 / 2$ cup & 17 \\
\hline Oil, canola & $1 / 2$ cup & 10 \\
\hline Oil, olive & 1 tablespoon & 17 \\
\hline Oil, other (including peanut, sesame, safflower, corn, sunflower, soybean) & 1 tablespoon & 83 or less \\
\hline Green tea, brewed in hot water & 1 tablespoon & 0.3 \\
\hline
\end{tabular}

\section{Explanation of figures}

Fig. 1: Biochemical similarity between vitamin $\mathrm{K}$ and warfarin molecules.

Fig. 2: Biosynthetic pathway for vitamin K-dependent production of gamma-carboxyglutamic acid.
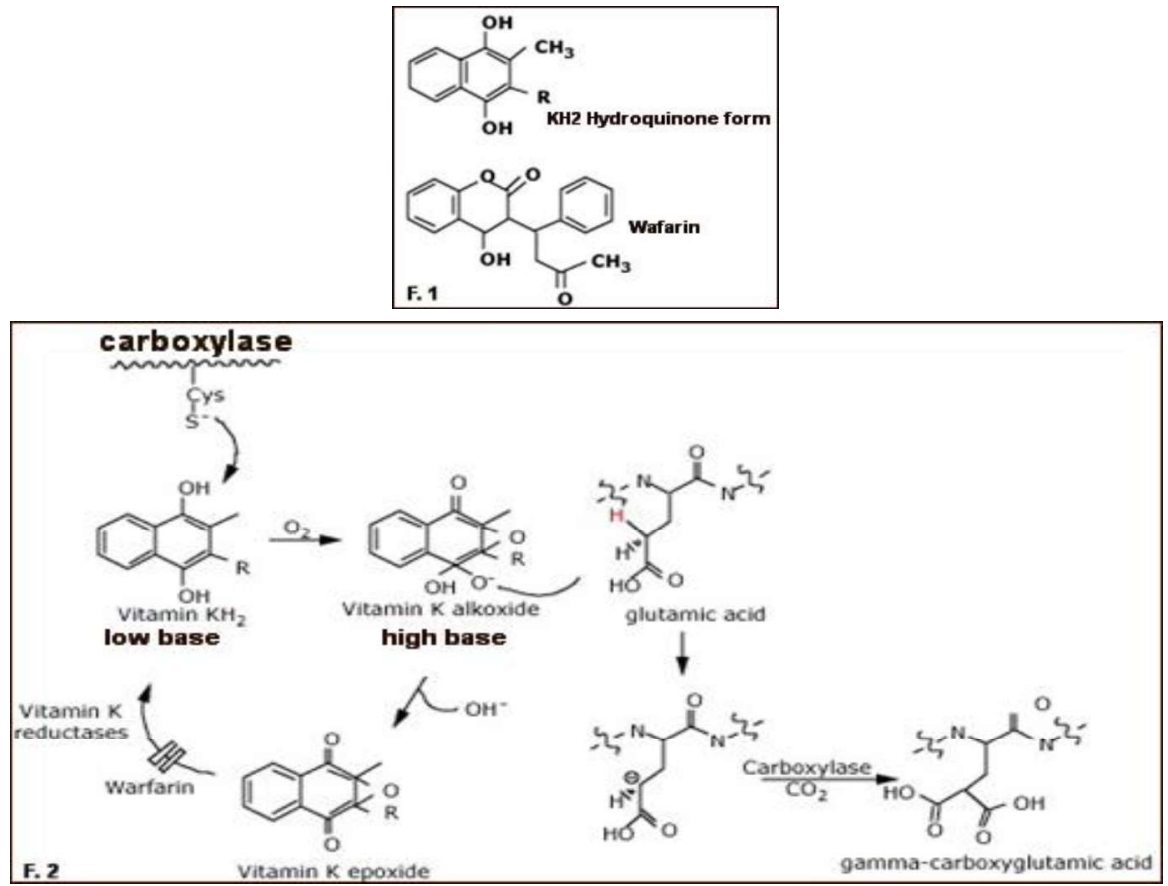